\title{
NOROESTE URBANOIDE: IDENTIDAD PARA UN COMPLEJO FERROVIARIO
}

\author{
URBANOID NORTHWEST: AN IDENTITY \\ FOR A RAILWAY COMPLEX
}

JADHER MARCOS BISPO DE SOUZA

Investigador independiente
La urbanización de Campo Grande está vinculada a la llegada de los trenes, dando lugar a nuevos barrios y culturas que se mezclaban con aquella población ya existente. A mediados de la década de los 90 se produce la desactivación y retiro de los rieles de su red urbana y en este contexto los espacios ferroviarios y su historia fueron perdiendo su identidad. Como capital de un estado brasileño se podrían brindar alternativas al complejo con soluciones utópicas, emergiendo en proyectos del siglo XXI que podrían servir para el transporte público, y así generar un giro en la economía y el turismo. Se realiza un análisis crítico sobre la realidad encontrada y la evolución del espacio histórico y urbano de Mato Grosso del Sur.

urbanismo, conservación del patrimonio, movilidad, rehabilitación urbana, historia
Recibido: 24 de mayo del 2019 / Aprobado: 7 de agosto del 2019 doi: 10.26439/limaq2020.n006.4818

Campo Grande's urbanization was linked to a railway track, giving rise to new neighborhoods and cultures that were mixed with the already existing population. In the mid-90s, the railway track deactivation and removal from its urban network occurred, and, in this setting, railway spaces and their history started losing their identity. As a Brazilian state's capital, alternatives with utopian solutions could be provided to the complex, resulting in 21st-century projects that could be used for public transportation, and thus generate a change of direction in the economy and tourism. This paper discusses the reality found in Southern Mato Grosso, as well as its historical and urban space evolution.

urban planning, heritage conservation, mobility, urban rehabilitation, history 


\section{INTRODUCCIÓN}

Figura 1.

Campo Grande,

Mato Grosso del

Sur, Brasi

Fuente: Guía de

Turismo de Brasil.

Recuperado de

https: //www.guia

doturismobrasil.

com/gastronomia/

3/MS/campo-gran

de/971

Diversas ciudades de todo el mundo mantienen sus historias protegidas, es así que los escenarios urbanos permanecen integrados en el espacio urbano a lo largo del tiempo y, también, adoptan nuevas estrategias y tecnologías para que no sean olvidados con el paso del tiempo. En Brasil ocurre lo contrario. Es comúnmente aceptado que muchos bienes históricos que traen "en sus venas" la historia de una colonia portuguesa o de un hecho importante para el órgano social brasileño están en ruinas o ya no existen debido a la degradación del tiempo, de los consumidores de drogas o de accidentes naturales.

El punto de enfoque de este artículo es la ciudad brasileña de Campo Grande, la capital del estado de Mato Grosso del Sur (figura 1), alegando que la ciudad tiene edificios históricos que, si se restauran, crearían fuertes escenarios históricos que resaltarían la "Ciudad Morena" de otras décadas.

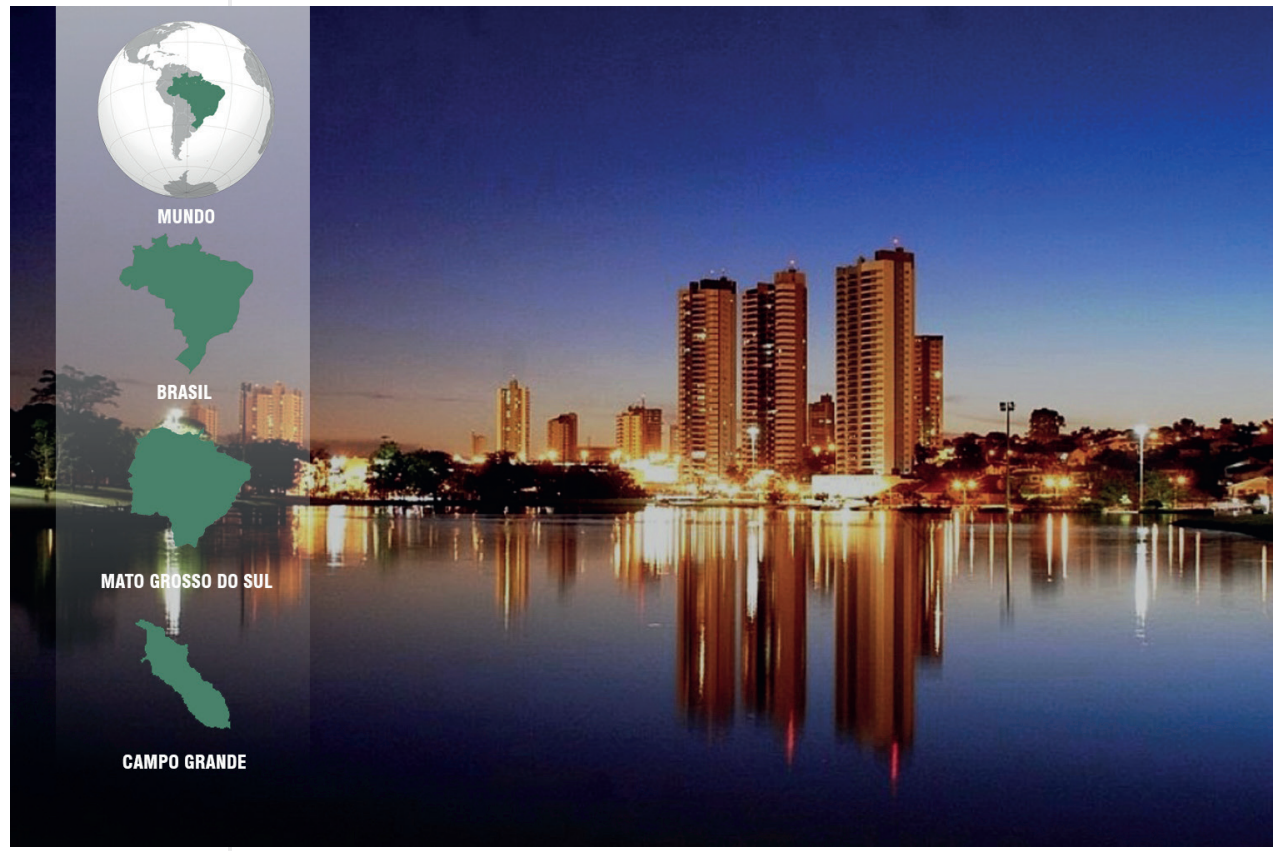

Como fundamento para este artículo, analizaremos el caso de la Explanada Ferroviaria, que está ubicada más al norte de la ciudad y cuenta con un gran espacio que podría ser ocupado para ofrecer programas ricos tanto cultural como socialmente, y en que la población residente intercambiaría experiencias, en cierto modo, con la población flotante. Desde el comienzo del territorio, es decir, el start, el proyecto utópico traería al contexto lo auténtico, lo original para lo que, en gran medida, el lugar ha sido destinado: el transporte (figura 2). 


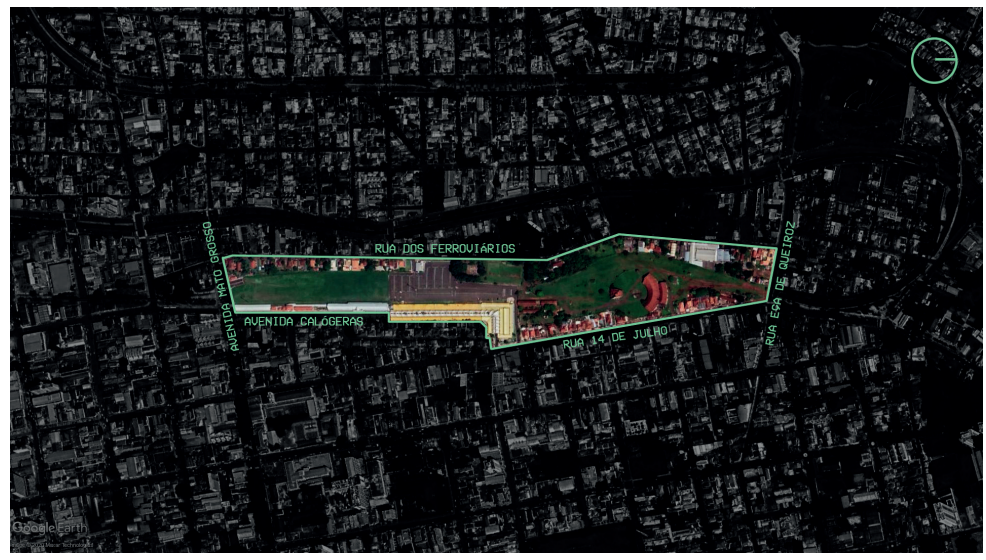

Pero, ¿qué ocurre con los espacios que anteriormente estaban ocupados y eran áreas pertenecientes al ferrocarril? ¿Cómo se beneficiaría la sociedad con la reestructuración, reactivación y rehabilitación del complejo ferroviario? Se podrá responder a estas preguntas a lo largo de este estudio, así como también verificar la información que respalda la propuesta de un proyecto completamente utópico para la ciudad.

Históricamente es incuestionable que la "Ciudad Morena" (como se conoce a la capital de Mato Grosso del Sur) tuvo un desarrollo basado en la economía ganadera, ya que poseía una geografía privilegiada. Asimismo, era un nexo comercial importante debido a que era una de las vías para llegar al norte desde el sur. Por lo tanto, la interconexión ferroviaria se llevó a cabo con la región más desarrollada de Brasil: el sureste, por medio de la llegada de Maria Fumaça de la Companhia Estrada de Ferro Noroeste do Brasil (Compañía Carretera de Hierro del Noroeste de Brasil). La historia que se desarrolla podría continuar. La intervención política en el espacio urbano, que no consideró la opinión de su población, ha estado pisoteando los planes de los habitantes excluyendo los deseos de los antiguos trabajadores del ferrocarril. Así, y en este contexto, el diseño del ferrocarril en la ciudad se transformó de tal modo que perdió gran parte de su espacio original para la realización de un proyecto diferente al esperado.

La gestión de la ciudad estaba causando que el espacio de la vía del tren se perdiera hasta llegar a convertirse en un espacio insignificante e inseguro que alguna vez ofreció "refugio urbano". Al poco tiempo, dicho refugio fue considerado algo inútil para los residentes y los que estaban de tránsito por la ciudad.

Si analizamos las relaciones de la población con la Explanada y, específicamente, la Estación Ferroviaria (figura 3), podemos notar que tanto la arquitectura (con respecto a sus usos) como la sociedad iban caminando juntas en el tiempo. La esencia de las vías del ferrocarril en la vida urbana y en la historia es perceptible en algunos lugares. De esa manera, según la Red Ferroviaria Federal Sociedad 
Figura 3.

Estación

Ferroviaria, en Campo Grande/

Elaboración

propia

Anónima (RFFSA, 1991), cada función, cada lugar hace referencia al espacio urbano, y participa en la construcción de la sociedad sin perder su esencia. Se puede afirmar que esto no es lo que sucedió en el suelo de Campo Grande.

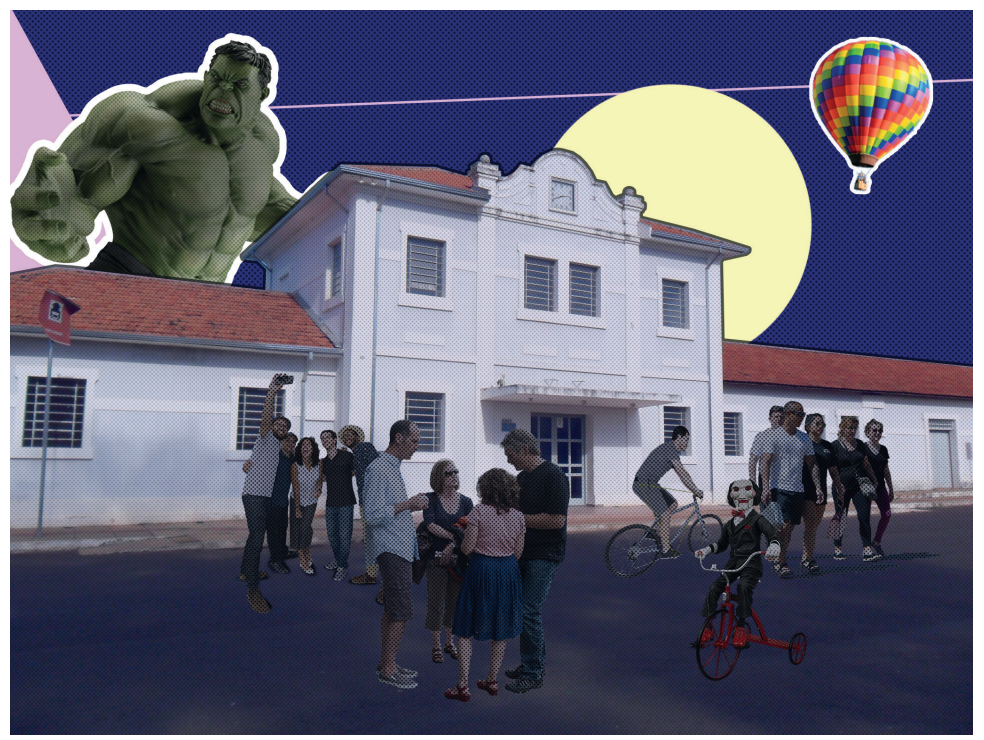

Muchos estudios y planificaciones provenientes de la propia gestión municipal caracterizan a este ambiente como un gran parque con diversas actividades de ocio y socialización, gastronomía, entre otras actividades. Sin embargo, olvidan que el acceso, o, mejor dicho, el tránsito para llegar a él debe ser más fluido y ágil, y para eso se requiere una movilidad eficiente. Campo grande, así como los grandes centros urbanos, según Vieira (2002), sufre los efectos de la falta de transportes eficientes, por lo que existe congestión, ruido, estrés, etcétera, que conducen a una mala calidad de vida en estos lugares.

Al salir de los límites del complejo, nos encontramos con los alrededores, que consisten en residencias para los trabajadores de la compañía de ferrocarriles Carretera de Hierro, y conservan la idea de que el rumbo urbanístico está vinculado con esta área. Según Souza (1918), cuando compuso el himno a la ciudad, la describió como un lugar que alguna vez fue un desierto. En esta metáfora se encuentra el inmenso campo inhabitado y dicha canción, escrita en prosa y olvidada por gran parte de la población, ya revelaba que para 1914, con la llegada de la EFNOB, iba a haber una transformación completa de lo urbano. Por lo tanto, los patrones, las técnicas de construcción, los materiales y las formas de los edificios, en ese momento nuevos para la población, también cambiaron el modus vivend $i^{1}$.

1 Modus vivendi es una expresión latina que significa "forma de vida". 
Con respecto a la utopía, la contemporaneidad exige, a través de la sociedad, la resolución de las necesidades de los espacios urbanos. Y, según Ghione (2013), la arquitectura y el urbanismo constituyen una de las mayores evidencias de ideas, valores e intereses que dirigen los objetivos de los políticos y socialistas de la sociedad. Según este autor, esto quiere decir que los edificios e intervenciones son formas encontradas por diferentes grupos que anhelan la supremacía sobre lo social y lo urbano.

La utopía se traduce como una respuesta a los problemas urgentes que atraviesan tanto los centros urbanos como la periferia, donde las cuestiones sociales, políticas y económicas no tienen solución. Esta palabra no tiene tiempo ni lugar, pero ha dado pie, dentro de la academia, de manera activa y reactiva, a los debates críticos del sistema y a las resoluciones urbanas y arquitectónicas de la época llamada "hoy".

Cada persona tiene un concepto distinto del entorno urbano, incluso aquellas personas que transitan por determinados espacios; tales conceptos o incluso significados derivan de las acciones del hombre que vive en el ambiente habitado. Según Lynch (1999), la ciudad no solo es una causa para ser percibida (y tal vez disfrutada) por la humanidad de diferentes clases y aspectos sociales, sino que debe entenderse como el producto de muchos constructores que, por razones de terceras personas, nunca deja de modificar su estructura. En este caso se argumenta que es por esta razón que la humanidad está en un proceso constante de reinvención e invención, tanto utópica como real en su espacio, lo que constituye su portafolio cultural y de vida.

En la actualidad predomina mayormente el consenso de las soluciones utópicas arraigadas y extendidas a través de las redes, donde los grupos, compuestos por miembros que tienen el mismo ideal, se forman con el propósito de debatir las soluciones del escenario en el que dichas asociaciones se insertan a través de creencias, costumbres, etcétera.

Con el paso del tiempo, ¿deberíamos dejar éde aspirar a la ciudad que queremos? ¿Es correcto decir que la utopía tiene sus días contados? Debe tenerse en cuenta que la búsqueda del ideal soñado, pero no cumplido, tiene sus sueños allí, plasmados en muchos tableros de dibujo y proyectos que terminan siendo mucho más coherentes que las diversas iniciativas políticas, legislativas, educativas y sociales que existen.

La máquina desempeña su papel fundamental en el proyecto utópico, los procesos digitales se han vuelto comunes a este tipo de arquitectura, y las formas en que se incorporan a los edificios y las ciudades son variadas.

Existe una ausencia de debates que, de conformidad con las leyes, lleven el patrimonio a una nueva fase o a un enfoque más moderno que vincule la tecnología con lo antiguo e histórico. No debería existir la difusión de la idea de que lo histórico y cultural de la ciudad esté disociado de las nuevas obras arquitectónicas. Es común difundir, en el caso del complejo ferroviario, métodos de 
transporte más modernos o incluso difundir los que algún día podrían existir, incluso analizando su importancia y su impacto en una ciudad consolidada. Si estudiamos las perspectivas de crecimiento de nuestras ciudades, resulta que debería existir una revisión de sus modelos y también deberían presentarse alternativas y estrategias sostenibles que garanticen un desarrollo adecuado.

La pregunta es la siguiente: ¿por qué las políticas de desarrollo urbano no están completamente relacionadas con sus ciudadanos creando así una retroalimentación a la sociedad, ya que el capital invertido debe ser utilizado en espacios públicos, transporte y cultura? Lo que se observa es la transformación de espacios - susceptibles a grandes avances- que son removidos.

Utópicamente, se esperan formas fluidas y con intensa conexión tecnológica del modelo de la fusión del siglo xx con el actual, un escenario que hace referencia al rumbo de la urbanización de la "Ciudad Morena" al actual Campo Grande, ya que

pensar en movilidad urbana es pensar sobre cómo organizar los usos y la ocupación de la ciudad y pensar en la mejor forma de garantizar el acceso de las personas y los bienes que ofrece la ciudad, no solo pensar en los medios de transporte y tránsito. (Santoro y Vaz, 2005)

\section{EL PUNTO DE PARTIDA, EL PATRIMONIO Y LA INVENCIÓN}

El área de la Explanada Ferroviaria ha sido objeto de mucho interés y, por consiguiente, de muchos estudios, ya que tanto sus autores locales como los foráneos han informado sobre las experiencias en dicho espacio y sus relaciones con todo el oeste, así como las buenas noticias que este emprendimiento trajo a esta parte desconocida de Brasil.

Es correcto decir que estamos hablando del interior de Brasil, una parte que todavía necesitaba mucha exploración para descubrir sus reales encantos; debido a que, históricamente, solo entre finales del siglo xIx y principios del siglo $\mathrm{xx}$, se dieron las primeras acciones con respecto al desarrollo urbano de la ciudad y, en cierto modo, a su diseño. Se puede observar, por medio de lo suscrito en las páginas de la obra del autor Congro (1919), que las culturas se entrelazaban con la ciudad y que los trabajadores, cubiertos de polvo, se mezclaban con los habitantes de la ciudad. Asimismo, es común encontrar en la academia debates y proyectos en relación con el área de la EFNOB, los cuales se intensificaron después de que — según Arruda (1995) - el Ferrocarril Estrada de Ferro, ya en 1950, perdiera su valor económico y social, ya que su valor simbólico aún se mantenía.

En 1996, el último tren de pasajeros pasó por la ciudad en dirección a Ponta-Porã, una ciudad fronteriza con Paraguay. A partir de este momento, se comenzaron a extrañar las locomotoras, los viajes, el movimiento en los bares, el comercio y los diversos emprendimientos de las calles 14 de Julho, 
Calógeras y Mato Grosso, las cuales comenzaron a incorporarse en la memoria del ciudadano de Campo Grande.

Según la historia y la experiencia en la ciudad, se puede afirmar que en el 2004 los rieles fueron eliminados de la red urbana de la peor manera: en silencio y en la oscuridad de la noche. No se consultó al pueblo, las nuevas propuestas arquitectónicas y urbanísticas no trajeron ningún beneficio, ni siquiera hubo espacio para un sueño utópico, pues las cortinas se cerraron en un abrir y cerrar de ojos.

El punto de partida para que la ciudad pudiera hacer de la EFNOB un patrimonio, se produjo de a pocos. Ya en 2009, se convirtió en patrimonio material declarado por el IPHAN (Instituto del Patrimonio Histórico y Artístico Nacional). Por lo tanto, según el propio organismo, hay 22,3 hectáreas y 135 edificios de mampostería y madera que se construyeron a partir de la expansión de las actividades ferroviarias en diferentes fechas, así como parte de los rieles que no se retiraron del ferrocarril de la zona urbana de la "Ciudad Morena".

Deben promulgarse diversas leyes patrimoniales para un proyecto en este ámbito, e incluso si los proyectos utópicos llegan a ser parte del partido arquitectónico, es evidente que, en general, el patrimonio no puede ser obstruido por ningún edificio a su alrededor, pues debe prevalecer de forma única, para que realmente constituya el escenario histórico de la ciudad.

El modo de invención del proyecto surge a partir del momento en que se toman en cuenta las relaciones sociológicas del complejo con el pueblo, de la situación en la que se encuentran algunos edificios de la EFNOB (figura 4), de la memoria de la población y de los antiguos ferrocarriles que todavía sueñan con la reactivación de ese lugar. En este caso, se consideran las palabras de Lavoisier: "Nada se crea, nada se pierde, todo se transforma", afirmando que podrían crearse nuevas formas de transporte, introduciendo la magnificencia del siglo XxI, que es parte de los procesos tecnológicos que se están introduciendo, acortando distancias y conectando/atrayendo personas para que se apropien de esos lugares.

Es cierto que el organismo responsable del patrimonio intenta dar valor a tales panoramas históricos y siempre tiene en sus planes invertir en la restauración y promoción de esos espacios. Antiguamente, el país había vivido épocas de gran inversión y fomento de la cultura. Sin embargo, en la actualidad se evidencia una confusión con respecto a lo político y económico.

Al proyectarse en ese espacio imaginariamente, se tienen en cuenta una infinidad de variantes que se entrelazan con las composiciones sociales, manifestaciones culturales públicas y tradiciones de la propia ciudad. El utopismo revelaría proyectos de diversas características, algunos con relaciones directas con su entorno, otros más privados y sin ninguna relación con sus calles y su historia.

En los años 60, Archigram pareció haber dado espacio a lo revolucionario y a una radicalidad análoga a su época. Así como Borges y Cyrino (2016), quienes afirman que también la revista, diseñada por jóvenes arquitectos británicos, 


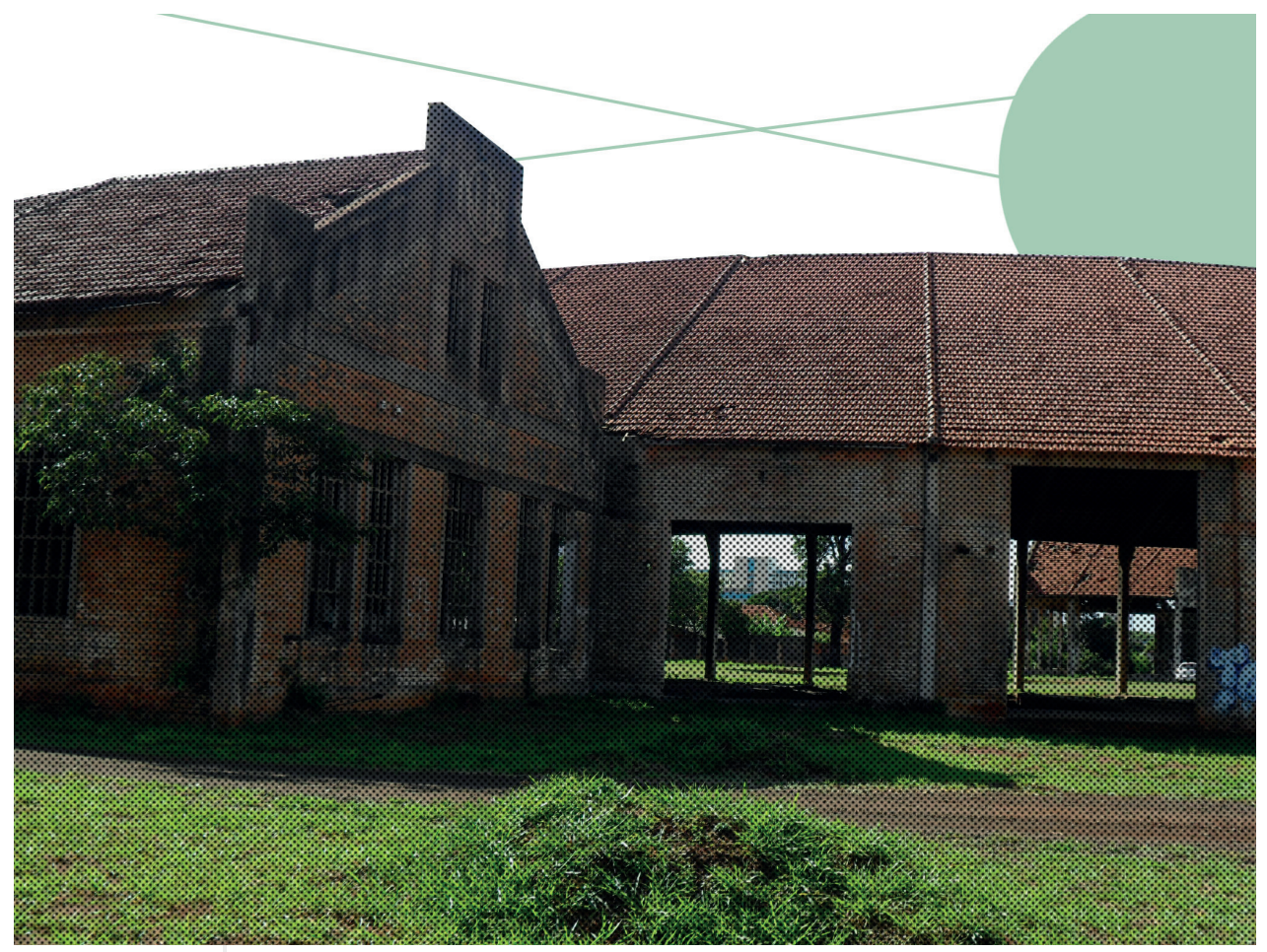

Figura 4. buscó soluciones extravagantes, a diferencia de lo que ya había sido cons-

Estado actual

de uno de los

edificios más

imponentes

de EFNOB, la

Rotonda

Fuente: archivo

personal truido e incluso dejando espacio para la ruptura de los límites de la tierra. Era el futuro, era lo imaginario lo que estaba emergiendo nuevamente en una época en que inclusive - según los autores - los sonidos de la guitarra eléctrica comenzaron a sonar aún más y la rebeldía juvenil aumentaba y se veía reflejada con nuevos cortes de cabello junto con los Beatles que cantaban, en ese entonces, Love Me Do en sus trajes y que pasaban a la siguiente canción, Lucy In The Sky With Diamonds con una excentricidad psicodélica, a la vez que se quitaban las chaquetas.

La invención, o más bien, la rehabilitación del área, ya parece ser utópica porque es una propuesta que requeriría volver al tiempo acercando los usos a los ya establecidos en el proyecto original. Para tener una breve noción de lo que se concibe como rehabilitación urbana, diremos que esta se apropia del concepto de arte descrito en el artículo 2 del Decreto Ley n. ${ }^{\circ}$ 307/2009 del 23 de octubre, Nuevo Régimen Legal para la Rehabilitación Urbana de Portugal. Se puede afirmar que la intervención es intrínseca a su significado. Es una intervención en la que el patrimonio urbano e inmobiliario permanece sin cambios, si no se moderniza con la construcción, demolición, reconstrucción, extensión, alteración, conservación o demolición de edificios. 
Debido a que es un Noroeste Urbanoide, dicho término sugiere la especificidad de la ciudad de Campo Grande, donde tal espacio se ha apropiado de la ciudad y no al revés, y no tiene interés de ser de otro lugar. Es importante decir que, en este sentido, la palabra "urbanoide" no tiene un significado peyorativo, sino que hace una referencia inherente a la ciudad, el espacio en el que se concibió la EFNOB.

Veloso (2007) señala que, desde el inicio, el proyecto tenía como principios modificar algo preexistente, que podía ser a escala micro o macro (edificios o contexto urbano) y en el caso de edificios históricos, se tenía en cuenta los significados especiales que eran inseparables del lugar. Lo más importante de todo es inventar, concebir algo que sea funcional, que sirva de base para un proyecto utópico que se pueda interpretar de diferentes maneras y, además, que sirva de base para otros proyectos. Aun así, según Veloso (2007, como se citó en Souza, 2016), actualmente existe la reutilización adaptativa presente en la arquitectura y el urbanismo, la inserción de nuevas formas del pasado, que no se basan en métodos de preservación de sus unidades estéticas y culturales. Por otro lado, pueden condenarlos a su propia muerte, ya sea por alteración o enmascarados escenográficos y epidérmicos de las fachadas, o por el vaciado de lo que generalmente se considera, en tiempos modernos, como la esencia misma de la arquitectura, el espacio interior (Veloso, 2007, p. 13).

El universo se ha vuelto práctico a lo largo de los años, por lo que estamos inmersos en el trabajo de nuestras mentes; y en nuestra charla interior ya existen frases preparadas que pueden expresar la búsqueda de más atajos para la vida: “iImagínese si hubiera una manera de hacer eso?”, “¿cómo sería la vida si pudiéramos estar en dos lugares a la vez?". En ese mismo ámbito podemos decir que el proceso de lo utópico, de la invención, está estrechamente relacionado con el trabajo dentro de nosotros al tratar de crear y establecer soluciones. La invención debe ser parte del futuro, el cual debe tener espacios cortos de tiempo entre un evento y otro, a fin de dejar espacio para lo nuevo.

\section{UTOPÍA VERSUS REALIDAD: EL CIELO ES EL LÍMITE}

En realidad, resulta que la gran mayoría de los proyectos utópicos, tanto para el área como para los problemas cotidianos establecidos en los debates, se complementan con la tecnología, pero en esencia traen la idea de la arquitectura interactiva donde todo el público es participativo y puede apropiarse del espacio, del objeto de estudio y de su propia forma de ver la sociedad.

Campo Grande se encuentra en un momento en que grandes transformaciones y desajustes conforman el espacio. En este contexto, encontramos una serie de obras inconclusas, espacios sin acceso para el usuario, ciclovías no conectadas y una cultura que se ha extinguido debido a los ritos políticos y de imposición. No existe un límite para la creación humana, especialmente en las academias, donde sus miembros provienen de diversas clases sociales y a veces aportan a su repertorio una diversidad cultural, religiosa y política. 
Figura 5

Diseño de cápsula de transporte, implementado en EFNOB y en la ciudad

Elaboración propia
Los modos de transporte se superpondrían a través de rieles por cápsulas de alta tecnología y alta velocidad (figura 5) que se elevarían desde la distancia del suelo, descongestionando el tráfico y creando una intermodalidad entre lo que ha sido creado y lo que ya existe, ya que, a pesar de ser una capital, no hay metro ni trenes que abastezcan la ciudad.

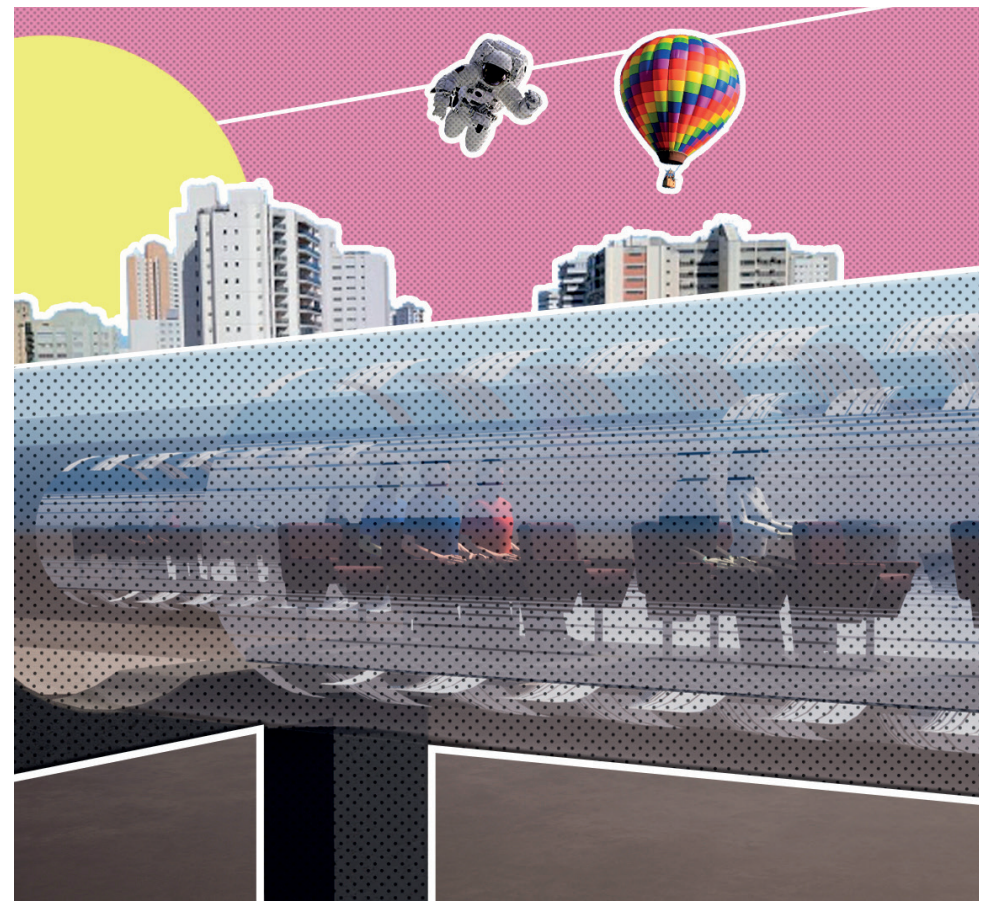

Los buses de tránsito rápido (BRT por sus siglas en portugués) son ineficientes y en las horas punta no son compatibles con la población. En cierta forma, la ciudad sufre de una falta de inversión en el sector transporte. La población más desfavorecida sufre con las tarifas y posee un sistema deficiente, sin ninguna cohesión que sea sinónimo de movilidad. Los automóviles desempeñan cada vez más protagonismo en los escenarios urbanos de Campo Grande, donde según Alouche (2008), el incremento del tráfico, con el rápido aumento de los vehículos de transporte privado, provoca la degradación de los centros urbanos debido a los fenómenos de asfixia. Esto se debe al difícil acceso y a la expansión de las ciudades a las periferias y los suburbios, lo que dificulta el desplazamiento de las personas dentro de la ciudad.

Se observa que el patrimonio en Brasil tiene leyes que rigen el reconocimiento del valor histórico. La norma federal, Decreto Ley n. ${ }^{\circ} 25$ del 30 de noviembre de 1937 "organiza la protección del patrimonio histórico y artístico nacional" (Constituição do Brasil: 1988), lo cual podría ser la solución para decidir los 
usos y composiciones en los tramos de la Explanada. Sin embargo, se sabe que el artículo 18 establece que no debería haber, "sin autorización previa del Servicio Nacional de Patrimonio Histórico y Artístico, [...] una construcción que impida o reduzca la visibilidad o coloque anuncios o carteles, de lo contrario se procederá con la destrucción de la obra o el retiro el objeto" (Constituição do Brasil: 1988). Pero lo que prevalece en la utopía es la ilusión basada en principios filosóficos, sociales, religiosos y políticos y la realidad a modificar, poniendo todo bajo control. En estos casos no es necesario seguir todo al pie de a la letra. En esta utopía los territorios y los proyectos llegan a la perfección, se rinden a la armonía e ironizan la realidad, pero visten ideales y perspectivas, como si se tratara del sueño de un niño.

En este caso, se tiene la planificación de cada área existente, ajustándose a la rehabilitación ya introducida en este estudio. Todo el proyecto del Noroeste Urbanoide y de la cápsula automática de transporte se basa en suprimir las grandes necesidades de la capital ante un problema que, aparentemente, no tiene fin: el transporte público y las áreas con carácter histórico que no se utilizan (figura 6).

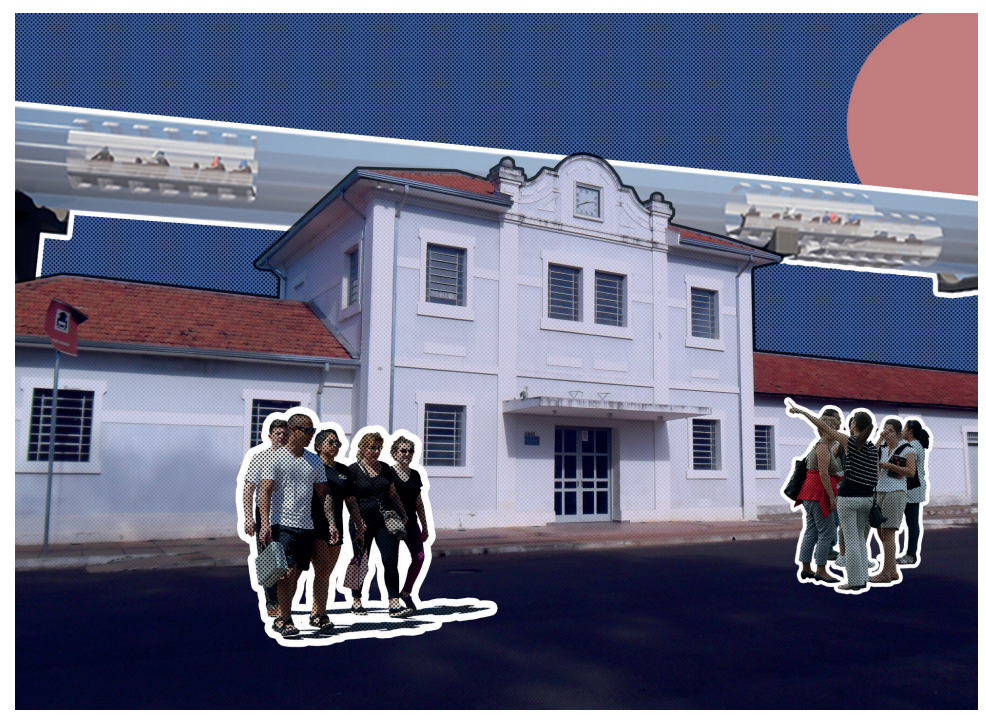

Figura 6.

El transporte de cápsulas y la estación de tren. Lo moderno y lo viejo

\section{Elaboración}

propia

La antigua estación ferroviaria se convertiría en una gran plataforma para la llegada y salida de las cápsulas, y la propia Explanada tendría las más variadas formas de hologramas tanto para información como para entretenimiento, de modo que los espacios libres se utilicen para dar forma al trayecto, ya sea para quien espera, para quien camina o para quien conduce por la zona, de manera que puedan contemplar los edificios, conocer la cultura y la historia olvidada de la capital.

En este caso, el cielo es el límite, ya que todas las formas de transporte ya no tendrían lugar en las vías del tren. Sin embargo, al mismo tiempo, eso apunta 
a un cambio en el paisaje urbano, pues lleva el movimiento y el futurismo a las escenas históricas. El desplazamiento rápido es algo anhelado por todo ciudadano de Campo Grande, que recientemente ha visto un cambio drástico en el tránsito: un aumento en la espera de llegar a su destino, un hecho que se debe al descontento en el uso del transporte público ineficiente y en el aumento del número de automóviles en las calles.

Los puntos que simbolizan las paradas de las cápsulas se fijarían en puntos estratégicos de la ciudad.

La estética de los puntos y de las cápsulas sería evidente, pues se busca destacar la visión de la ciudad o incluso toparse con los cielos de Campo Grande. El espíritu tecnológico se desplazaría rápidamente por los aires, promovería lo inalcanzable hasta entonces e impresionaría al turista. La práctica conservadora o, mejor dicho, el edificio construido no estaría contrapuesto, sino que sería parte del entorno urbano histórico. En este pensamiento, si el proyecto utópico trabaja junto con su entorno y con el patrimonio histórico, lograría una atracción y apreciación masiva de un lugar previamente deconstruido por el olvido de las nuevas generaciones y el abandono parcial de las generaciones anteriores.

Se podría decir que el valor cultural aumentaría en el caso de que proyectos más utópicos pudieran convertirse en realidad; del mismo modo, el turismo debe fomentarse con más fuerza y debe reforzar el alto título de la capital de Mato Grosso del Sur. Los recortes y las imaginaciones son parte de la utopía, $y$ traen consigo una realidad que no fue adquirida por una sociedad, pero que podría vivirse en un espacio de tiempo y entorno de una determinada ciudad. Para tener un concepto basado en lo que se dice, según De Souza (2016), el entorno ferroviario debe colocarse en un lugar que hay arraigado edificios únicos (figura 7), propios para tal uso. Lo que tenemos en mente es lo que anhelamos mediante proyectos urbanísticos que satisfagan las necesidades de la capital, la infraestructura del transporte público y el turismo, fomentando así la economía de la capital y haciendo de esta ciudad no solo un pasaje, sino algo que busca la permanencia de todos los visitantes.

Figura 7

La ampliación

del Complejo

Ferroviario NOB,

en la avenida

Calógeras

Elaboración

propia

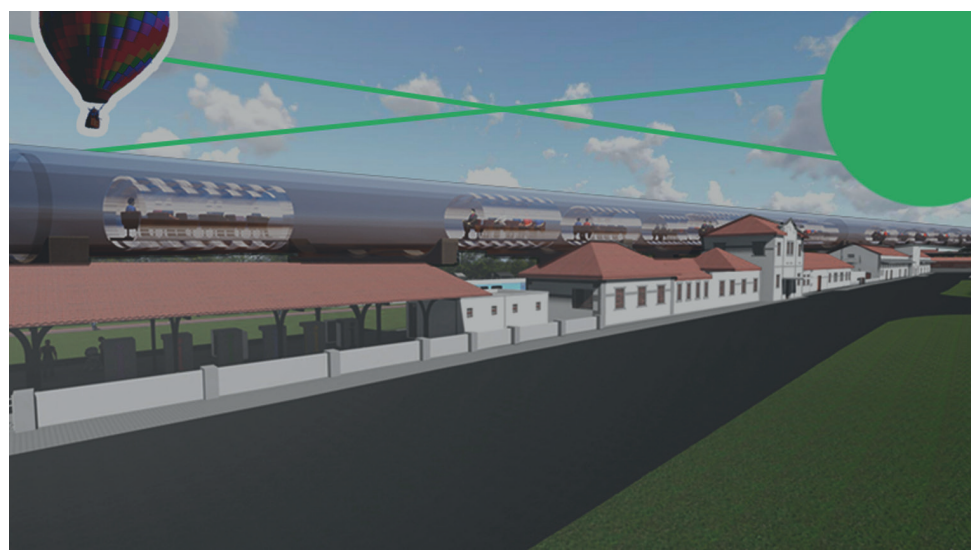


La obra arquitectónica y paisajística de la Explanada es una utopía en todos los sentidos, ya que cada día muestra a los habitantes que existe una esperanza para el complejo; sin embargo, está destinada a la ruina (figura 8). Muchos problemas sacuden a Campo Grande, una ciudad que es realmente hermosa, llena de paisajes naturales, pero tiene un centro urbano que es estresante y necesita los medios para que se automatice y se incluya lo arcaico.

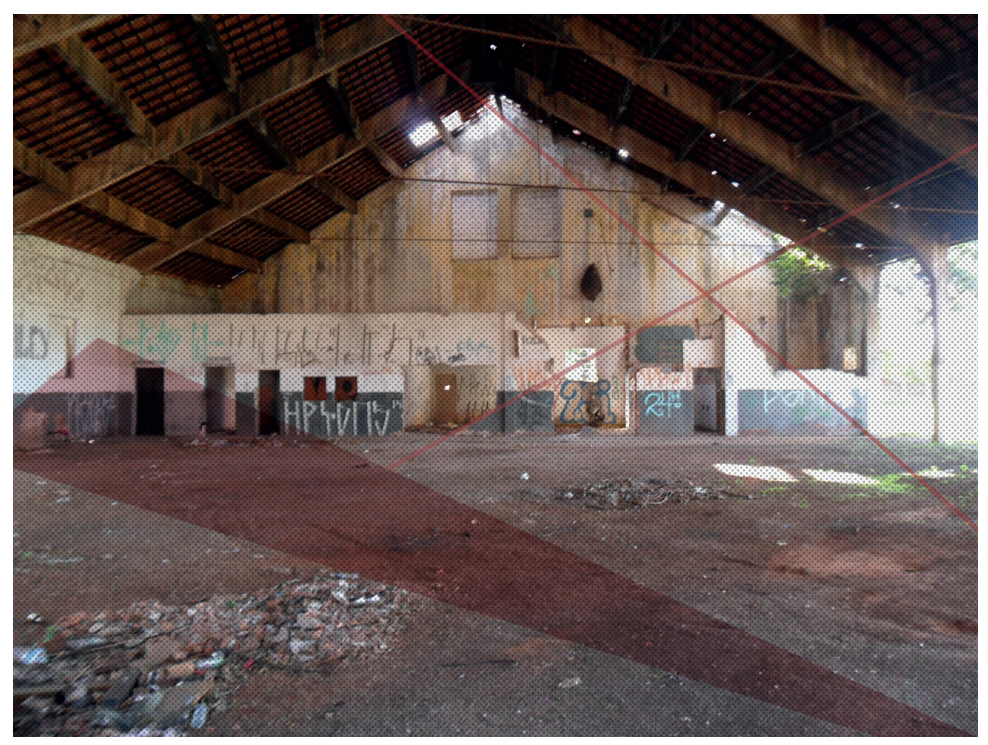

\section{Figura 8.}

Situación de abandono en algunos de los edificios de

\section{EFNOB}

\section{Archivo}

fotográfico

del autor

No se descarta la idea de que la utopía es una producción arquitectónica basada en el concepto de adquirir mejores formas de vida, pero que permanece documentada en los campos y estudios teóricos. Excluir estos proyectos e ideales no puede ser la solución, más bien, adoptarlos como una reinvención del espacio de una ciudad, de un entorno o de un organismo social ya establecido es plausible, ya que detrás de todo este sistema de ideas yace un crítica y proyección de resultados al sistema que vive una sociedad. En conclusión, mediante la utopía se puede percibir el avance.

\section{REFERENCIAS}

Alouche, P. (2008). Um transporte moderno, sustentável e urbanisticamente correto para as cidades brasileiras. Revista dos Transportes Públicos, (118), pp. 35-44.

Arruda, G. (1995). Ferrovia noroeste do Brasil: o último trem para o sertão. Brasil: Prefeitura Municipal de Campo Grande (Cadernos de Estudos Urbanos). 
Borges, V. y Cyrino, T. (2016). Utopia e produção arquitetônica. Archigram, uma nova forma de teoria. Arquitextos. Recuperado de http://vitruvius.com.br/ revistas/read/arquitextos/17.196/6221

Constituição do Brasil. (1988). Decreto-Lei n. ${ }^{\circ}$ 25, de 30 de novembro de 1937. Organiza a proteção do patrimônio histórico e artístico nacional. Río de Janeiro, 1937. Recuperado de https://www.planalto.gov.br/CCIVIL_03/ Decreto-Lei/Del0025.htm

De Souza, J. (2016). NOROESTE: Redesenho e projeção da ferrovia em Campo Grande. Trabalho de Conclusão de curso (Bacharelado em Arquitetura e Urbanismo) - FAENG - Curso de Arquitetura e Urbanismo, Universidade Federal de Mato Grosso do Sul. Campo Grande, p. 198.

Ghione, R. (2013). Arquitetura, ideologia e utopia. Resenhas Online, (12)139.04. Recuperado de http://www.vitruvius.com.br/revistas/read/resenhasonline /12.139/4802

Congro, R. (1919). O municipio de Campo Grande-O Estado de Mato Grosso. Publicação official.

Lynch, K. (1960). A imagem da cidade. São Paulo: Martins Fontes.

Rede Ferroviária Federal S. A. (1991). Superintendência de Patrimônio. Gerência de Preservação do Patrimônio Histórico Ferroviário. Manual de Preservação de Edificações Ferroviárias Antigas. Rio de Janeiro: RFFSA, 1991. RFFSA/ PRESERFE.

Santoro, P. y Vaz J. (2005). Cartilha Mobilidade urbana é desenvolvimento urbano. Instituto Polis. Recuperado de http://www.polis.org.br/publicacoes_interno. asp?codigo $=194$

Souza, T. (1918). Hino de Campo Grande. Campo Grande. Recuperado de http:// www.campogrande.ms.gov.br/gapre/canais/hino-de-campo-grande-ms/

Veloso, M. (2007). O moderno no passado: projetos de reusos adaptativos como estratégia de conservação do patrimônio histórico edificado. Porto Alegre. Anais do III Seminário Projetar, (00), pp. 00-13. Recuperado de http://projedata.grupoprojetar.ufrn.br/dspace/bitstream/123456789/34/1/ Projetar\%202007\%20VELOSO.pdf

Vieira, W. (2002). Noroeste do Brasil: Em trilhos e prosas. Campo Grande: Plus Assessoria de Comunicação Social. 